\section{CJD and the eye}

In the 1980s, as both practitioners and members of society, we had first to become familiar with, and then to accommodate, the new and frightening statistics of HIV infection. These remain no less appalling, especially in the developing world, but thankfully the agent is identified and increasingly well understood; it can be screened for, guarded against and there is increasingly effective treatment.

In the 1990s mention of transmissible spongiform encephalopathies (TSE) emerged from the small print of medical text books to proliferate in research journals and provide regular copy in newspaper and media headlines. This group of diseases is now known to result from an isomeric change in a normal structural cell membrane, prion protein (pronounced 'pree-on' by Prusiner its discoverer ${ }^{1}$ ). The abnormal protein accumulates in cells and progressively interferes with function, particularly in neurones, and is remarkably resistant to all routinely used forms of clinical decontamination. ${ }^{2}$

Bovine spongiform encephalopathy (BSE) was first recognised in $1986,{ }^{3}$ but it was not thought likely that it would pose a major threat to human health. ${ }^{4}$ In 1988 measures to prevent further animal cases being acquired through infected feed were introduced ${ }^{5}$ and the following year certain high-risk animal tissues were banned from the human food chain. ${ }^{6}$ In March 1996 it was reported that 10 human cases of a new variant of Creutzfeldt-Jakob disease might be linked to exposure to the BSE agent, ${ }^{7}$ although exactly how this may have occurred is still not clear.

Since then we have had to come to terms with the slaughter of nearly 4 million cattle ${ }^{8}$ as a further preventive measure and the steady appearance of more cases of variant Creutzfeldt-Jakob disease (vCJD). To date over 50 cases of vCJD have been diagnosed in the UK, with two in France ${ }^{9}$ and one in Eire. ${ }^{10}$ The extent of the likely human epidemic is unknown and it is still too early to make any sensible predictions. ${ }^{11}$ There is also, as yet, no treatment for established clinical disease and no proven prophylactic measures for those who may have been exposed to infection.

In contrast to sporadic classical Creutzfeldt-Jakob disease, abnormal prion protein has been detected in the peripheral lymphoid tissue in people with vCJD. ${ }^{12,13}$ This probably reflects the exposure to the causative agent via a peripheral route such as ingestion. It
ANDREW TULLO, ROGER BUCKLEY, MIKE PAINTER

does give rise to the concern that the human population may be exposed through medical interventions to a greater range of potentially infected tissues than has been the case with classical CJD. One of the most visible signs of this concern is the fact that the blood products for use in the UK are now only made from plasma sourced from other countries.

Against this background an incident occurred in $1997^{14,15}$ when three patients in England received a cornea or sclera from a donor in Scotland with classical CJD; the patients concerned may yet develop this condition. This was a stark reminder that it was a corneal transplant in 1974 in the USA ${ }^{16}$ which provided the first evidence of human-to-human transmission of a TSE, to be followed by over 200 subsequent incidences due to dura mater and human growth hormone. ${ }^{17}$ The incident raised important issues about adherence to protocols for ocular tissue donation, and eye banking. This has served to improve and highlight guidelines ${ }^{18}$ and to prompt a debate about just how we should now proceed with investigations and operations, and the cleaning of instruments and devices in ophthalmic practice.

In this issue of Eye in the second of two papers, ${ }^{19}$ Lueck and colleagues provide a comprehensive review of the literature informing us that many patients with sporadic CJD have visual disturbances and may even present to an ophthalmologist. However, the notion that individuals with no neurological signs of prion disease may be capable of transmitting vCJD during any routine operation by contamination of instruments, has caused consternation in the Department of Health, not least because abnormal prion protein has been found in the tonsils and appendix of those with vCJD. $^{12,13}$

There is no firm evidence that either classical CJD or vCJD has been transmitted by ophthalmic devices or surgical instruments, though intracerebral electrodes during stereotactic encephalography and neurosurgical instruments ${ }^{20}$ have been responsible. However, degenerative changes are seen in the trigeminal ganglia. $^{21}$

There is also no published research on the distribution of abnormal prion protein in the eyes of people diagnosed as having any form of CJD. There is one report of infectivity being detected in the corneal epithelium of a hamster experimentally infected with transmissible

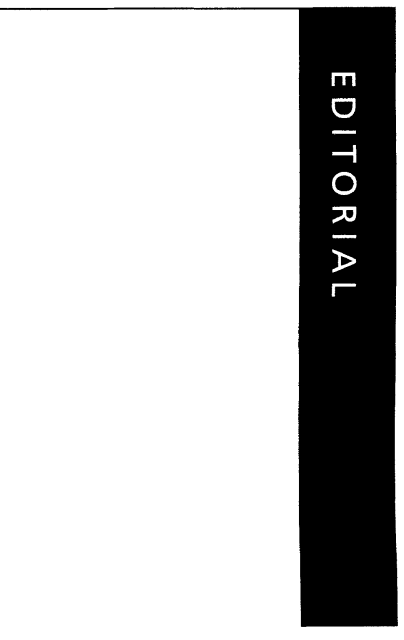

A. Tullo

Chairman of Ocular Tissue Standards and Audit Group Royal College of

Ophthalmologists

R. Buckley Member of the General

Optical Council and Chairman of its Standards Committee

Spokesman for Contact Lens Affairs Royal College of Ophthalmologists

M. Painter

Consultant in

Communicable Disease

Control

Manchester Health

Authority

Mr A. Tullo

Manchester Royal Eye

Hospital

Oxford Road

Manchester M13 9WH, UK 
mink encephalopathy, ${ }^{22}$ and more recently prion protein has been demonstrated in the trigeminal ganglia after experimental infection into both the tooth pulp and the peritoneum. $^{23}$

Nevertheless, the practices of ophthalmology and optometry have been identified as deserving special attention and in July 1999 the Department of Health issued a statement, without prior consultation with professional bodies, that contact lenses should never be used on more than one patient. This caused a good deal of anxiety amongst NHS staff and optometrists and amongst the public to whom they are expected to proffer advice. After further consideration in October 1999 the Medical Devices Agency effectively reiterated the same advice, ${ }^{24}$ recommending devices that touch the eye during examination - which would include tonometers, biometers and examination contact lenses, and prosthetic devices - 'should where practicable and where this does not compromise clinical outcome, be restricted to single patient use'.

Although it would be largely possible for optometric practice in the high street to implement the recommended changes, not least because of the moves in preference towards soft contact lenses, it would inhibit the expanding role of optometry in primary care. It is difficult to see how these recommendations within hospital departments could be met without services (and some research projects) grinding to a halt. This provides a challenging opportunity to discuss the relative risk of procedures and operations. At the request of the Department of Health, representative working parties of the ophthalmic and optometric communities are discussing a pragmatic reduction of risk factors and in particular asking the following questions:

1. In what areas of practice can we develop and afford to introduce disposable instrumentation and devices on a routine basis and who will pay for them?

2. What measures should we take when operating on a patient with non-ocular symptoms which are possibly due to CJD, such as mild dementia?

3. Are there some ophthalmic procedures which may be more likely to pose more of a risk than others, such as toothed versus tying forceps?

4. Are there some ophthalmic instruments which may be more likely to contaminate devices or instruments, such as retinectomy versus iridectomy?

5. Is it permissible to re-use disposable instruments such as keratomes or phaco tips during cataract surgery, designed for convenience or sharpness rather than avoidance of infection, and, if not, who will pay for such a large increase in single usage?

6. What shall we tell the patient who has had surgery involving the same instruments previously used on an individual who subsequently turns out to have either form of CJD, assuming.we are able to trace instruments and the patients at risk?

7. Can any further procedures be introduced to eye donation, processing and ocular tissue transplantation to reduce theoretical risk of transmission?
Pending the emergence of implementable guidance from the Department of Health, readers are encouraged to absorb and decide for themselves how best they can answer these important questions in their patients' best interest. Such an approach should include: questioning the absolute need for any procedure, the rationalisation of all methods of investigation and intervention (e.g. the numbers of surgical instruments used), and entering into what may turn out to be a constructive dialogue with designers and manufacturers of devices and instruments. ${ }^{25}$

\section{References}

1. Prusiner SB. The prion disease. Sci Am 1995;272:30-7.

2. Taylor DM. Inactivation of SE agents. Br Med Bull 1993;49:810-21.

3. Wells GAH, Scott AC, Johnson CT, Gunning RF, Hancock $\mathrm{RD}$, Jeffrey $\mathrm{M}$, et al. A novel progressive spongiform encephalopathy in cattle. Vet Rec 1987;121:419-20.

4. Southwood R. Report of the working party on bovine spongiform encephalopathy. London: HMSO, 1989.

5. The Bovine Spongiform Encephalopathy Order 1988. Statutory Instrument 1039. London: HMSO, 1988.

6. The Bovine Offal (Prohibitation) Regulations 1989. Statutory Instrument 2061. London: HMSO, 1989.

7. Will RG, Ironside JW, Zeidler M, Cousens SN, Estibeiro K, Alperovitch A, et al. A new variant of Creutzfeldt-Jakob disease in the UK. Lancet 1996;347:790-1.

8. http:/www.maf.gov.uk/animalh/bse/index/html.

9. Deslys JP, Lasmezas CL, Streichenberger N, Hill A, Collinge $\mathrm{J}$, Dormont $\mathrm{D}$, et al. New variant Creutzfeldt-Jakob disease in France. Lancet 1997;349:30-1.

10. The Irish Times. Dublin: 26 August 1999.

11. Ghani AC, Ferguson N, Donnelly CA, Hagenaars TJ, Anderson RM. Epidemiological determinants of the pattern and magnitude of the vCJD epidemic in Great Britain. Proc $R$ Soc Lond 1998;265:2443-52.

12. Hill AF, Zeidler M, Ironside J, Collinge J. Diagnosis of new variant Creutzfeldt-Jakob disease by tonsil biopsy. Lancet 1997;349:99-100.

13. Hilton DA, Fathers E, Edwards P, Ironside JW, Zajicek J. Prion immunoreactivity in appendix before clinical onset of variant Creutzfeldt-Jakob disease. Lancet 1998;352:703-4.

14. Tullo AB. CJD and the Eye. Focus, Royal College of Ophthalmologists, Autumn 1998;1-2.

15. Allan B, Tuft S. Transmission of Creutzfeldt-Jakob disease in corneal grafts. BMJ 1997;315:1553-4.

16. Duffy P, Wolf J, Collins G, Devoe AG, Streen B, Cowen D. Possible person-to-person transmission of Creutzfeldt-Jakob Disease. N Engl J Med 1974;290:692-3.

17. Brown P, Preece MA, Will RG. 'Friendly fire' in medicine: hormones, homografts and Creutzfeldt-Jakob disease. Lancet 1992;340:24-7.

18. www.rcophth.ac.uk

19. Lueck CJ, Mcllwaine GC, Zeidler M. Creutzfeldt-Jakob disease. II. Ophthalmic and neuro-ophthalmic features. Eye 2000;14:291-301.

20. Lueck CJ, Mcllwaine GC, Zeidler M. Creutzfeldt-Jakob disease and the eye. I. Background and patient management. Eye 2000;14:263-90.

21. Guiroy DC, Shankar SK, Gibbs CJ, Messenheimer JA, Dass S, Gajdusek DC. Neuronal degeneration and neurofilament accumulation in the trigeminal ganglia in Creutzfeldt-Jakob disease. Ann Neurol 1989;25:102-6.

22. Marsh RE, Anson RP. Transmissible mink encephalopathy infectivity of corneal epithelium. Science 1975;187:656.

23. Ingrosso L, Pisani F, Pocchiari M. Transmission of the $263 \mathrm{~K}$ scrapie strain by the dental route. J Gen Virol 1999;80:3043-7

24. Medical Devices Agency MDA AN 1999 (04).

25. Tullo AB, Taylor DM. CJD and ophthalmic instruments [letter]. Br J Ophthalmol. 2000;in press. 